\title{
Evaluation of the Role of Endoscopic Endonasal Surgery in Management of Orbital Complications of Rhinosinusitis
}

\author{
Omar Abd El-Moniem El-Banhawy", Ibrahim Abd El-Shafy El-Hateem ${ }^{1}$, \\ Esam Abd El-Wanis Behery ${ }^{1}$, Hassan Gamal El-Din Farahat ${ }^{2}$, Osama Mohamed Salah El-Naqib ${ }^{1}$, \\ ${ }^{1}$ Otorhinolaryngolog Department, Faculty of Medicine, Menoufia University, Shebein Elkom, Menoufia, Egypt \\ ${ }^{2}$ Ophthalmology Department, Faculty of Medicine, Menoufia University, Shebein Elkom, Menoufia, Egypt
}

Email address:

osamanakeeb@yahoo.com (O. M. S. El-Naqib)

To cite this article:

Omar Abd El-Moniem El-Banhawy, Ibrahim Abd El-Shafy El-Hateem, Esam Abd El-Wanis Behery, Hassan Gamal El-Din Farahat, Osama Mohamed Salah El-Naqib. Evaluation of the Role of Endoscopic Endonasal Surgery in Management of Orbital Complications of Rhinosinusitis. Advances in Surgical Sciences. Vol. 3, No. 1, 2015, pp. 1-7. doi: 10.11648/j.ass.20150301.11

\begin{abstract}
The methods for the treatment of orbital complications of rhinosinusitis are often debated: conservative, surgical or combined. Surgical options include both endoscopic and open surgery. However, in the era of endoscopic surgery of the nose and paranasal sinuses, there are still no clear advantages of these techniques over open interventions. Therefore, our study aimed to clarify and evaluate the results of intranasal endoscopic procedures performed in individuals with orbital complications of rhinosinusitis in search for optimal treatment of this group of patients. 30 patients were divided based on Velasco classification into 3 groups; $1^{\text {st }}$ group (14 patients) for patients with orbital cellulitis, $2^{\text {nd }}$ group (10 patients) for patients with subperiosteal orbital abscess and the $3^{\text {rd }}$ one ( 6 patients) was for patients with intraorbital abscess. Endoscopic endonasal surgery was done for all patients in group II and III and in 4 patients indicated for surgery in group I. Our result showed a highly significant postoperative improvement in proptosis, ocular motility, diplopia and vision acuity. Conclusion: Endoscopic Sinus Surgery offers a convenient, safe, and effective alternative to open procedures and can be successfully performed in well-selected cases of orbital complications of rhinosinusitis with many advantages.
\end{abstract}

Keywords: Endoscopic Endonasal Surgery, outcome and advantages, Orbital Complications of Rhinosinusitis

\section{Introduction}

Complications in acute rhinosinusitis (ARS) or chronic rhinosinusitis (CRS) are orbital $(60-75 \%)$, intracranial (15-20\%) or osseous (5-10\%) (Chandler et al., 1970).

Orbital infections were initially classified into five stages by Chandler and later modified by Moloney, Kastenbauer, Stammberger and Mortimore.

However, the most widely used classification was introduced by Chandler et al., published in 1970, but these classifications did not consider the orbits anatomical characteristics. Valesco et al proposed a new, more objective classification classifying orbital complications of rhinosinusitis into 3 classes as follow:-

- Orbital cellulitis.

- Subperiosteal abscess.

- Orbital abscess (Valesco et al., 2007).

Treatment of stages (I) is mostly conservative in the form of parentral broad spectrum antibiotics. One should keep a low threshold for surgical intervention within $24-28 \mathrm{~h}$ if patients are poorly responding to the antibiotics, while surgery is always indicated in more advanced stages especially with worsening visual acuity (Siedek et al., 2010).

Conventionally, the orbital abscess (subperiosteal and intraorbital) is drained via an external incision and sinus surgery is performed at the same time to remove the focus of infection. More recently, successful treatment both of the sinuses and the orbit has been accomplished endoscopically via an intranasal endoscopic approach with little morbidity, easy identification of anatomical structures, physiological drainage of the sinuses and superior cosmetic result (Strek et al., 2008).

The purpose of the article is to clarify and evaluate the results of intranasal endoscopic procedures performed in individuals with orbital complications of rhinosinusitis in search for optimal treatment of this group of patients. 


\section{Patients and Methods}

Thirty patients were selected from ENT outpatient clinic or refered by Ophthalmology Department of the Menofia University Hospital.

Patients with orbital complication of sinogenic origin were those selected. The inclusion criteria of our study were orbital complications of sinogenic origin, while exclusion criteria were suspected fungal infection, any orbital pathology not of sinogenic origin as well as suspected cavernous sinus thrombosis.

These patients were subjected to:

1. History taking.

2. physical examination:

A. General examination.

B. Endoscopic nasal examination using $0^{\circ}$ and $30^{\circ}$ endoscope.

C. Ophthalmological examination: visual acuity, extraocular movement, and degree of edema and proptosis.

D. Neurological examination.

3. radiological evaluation including:

E. Computed Tomography on orbit, nose and paranasal sinuses coronal / axial, with and without contrast.

F. Magnetic Resonance Imaging (in selected cases) on orbit, nose and paranasal sinuses with and without contrast (when indicated).

4. Routine laboratory investigations.

5. Medical treatment in all patients consisted of intravenous broad spectrum antibiotics; this was also combined with intranasal decongestants and analgesics.

The decision to proceed with Endoscopic endonasal Surgery (EES) was based on the lack of a clinical response after 24 hours of parenteral antibiotics and/or the presence of one or more of the following alarming signs:

A. CT proved subperiosteal or orbital abscess.

B. Deterioration in visual acuity.

C. Continuing fever after 24 hours of medical treatment.

D. Clinical deterioration after 48 hours.

E. Relative afferent pupillary defect.

(Garcia\& Harris, 2000).

\subsection{Technique of EES}

All procedures were performed under general anesthesia. The technique described by Messerklinger and Stammberger (1991) and Lusk (1992) was essentially applied. In all procedures, $0^{\circ}$ and $30^{\circ}$ nasal endoscopes were used. The surgical steps included local nasal decongestion, uncinectomy. Maxillary sinus clearance was accomplished by widening the maxillary ostium (when indicated). The anterior and posterior ethmoid sinuses were cleared, respectively. Transethmoid sphenoidotomy was done if indicated.

In cases where lamina papyracea was intact, a vertical cut was made on the anterior aspect using a Freer's elevator. The bony plate was elevated medially, and the purulent contents were evacuated, the frontal sinus (if indicated) was opened using Giraffe forceps. The purulent material and granulation tissue were sent for histopathological examination and culture.

The thirty selected patients were divided based on Velasco classification into 3 groups; $1^{\text {st }}$ group (14 patients) for patients with orbital cellulitis, $2^{\text {nd }}$ group (10 patients) for patients with subperiosteal orbital abscess and the $3^{\text {rd }}$ one ( 6 patients) was for patients with intraorbital abscess. Endoscopic endonasal surgery was done for all patients in group II and III and in 4 patients indicated for surgery in group I (Table 1).

Evaluation of surgery and follow up (for 12 months): including assessment of intraoperative and postoperative surgical complications as well as surgical outcome. Our post operative outcomes parameters were the degree of proptosis reduction, vision improvement, ocular motility improvement and resolution of diplopia. Furthermore, rate of recurrence, duration of hospital stay, return to normal life activity and work were evaluated.

\subsection{Statistical Analysis}

The data were collected, tabulated, and analyzed by SPSS (statistical package for social science) version 17.0 on IBM compatible computer.

\subsection{Two Types of Statistics were Done}

- Descriptive statistics [e.g. percentage (\%), mean (x) and standard deviation (SD)],

- Analytic statistics: which include the following tests: -

1) Chi-square test $\left(\chi^{2}\right)$ : was used to study association between two qualitative variables.

2) Mann Whitney $U$ test (U): a non parametric test of significance used for comparison between two groups not normally distributed having quantitative variables.

3) Kruskal-Wallis test (K): a non parametric test of significance used for comparison between more than two groups not normally distributed having quantitative variables.

P-value of $<0.05$ was considered statistically significant.

\section{Results}

There was no statistically significant difference between the percentages of stages in adults and children or in males and females.

The most common disorder seen on admission was proptosis $(46.7 \%)$. Reduction of visual acuity was less common (36.7\%), ocular motility affection (ophthalmoplegia) (30\%) and diplopia (33.3\%).

Indication for surgery (Endoscpic Endonasal Surgery) was obligatory in stages II and III. For stage I, conservative medical treatment is the mainstay unless one or more of alarming signs indicating surgical intervention appeared (Table 2).

The cases of orbital cellulitis were effectively managed by intravenous antibiotics except for 4 cases , 2 of them developed subperiosteal abscess under conservative treatment, the other 2 cases showed no improvement and even deterioration under conservative medical treatment. These 4 
cases were surgically managed (Table 2).

There was a highly significant postoperative improvement in proptosis, ocular motility, diplopia and vision acuity (Table $3)$.

Regarding the postoperative hospital stay, children had significant shorter mean hospital stay than adults (4.60 vs. 5.27 days) with mean overall hospital stay of (4.98 days) Table (4).

The return to normal daily home activity was in the $10^{\text {th }}$ to $14^{\text {th }}$ postoperative day with a mean of $11.8^{\text {th }}$ day return. Return to work was from $14^{\text {th }}$ to $21^{\text {th }}$ day with a mean of $16.7^{\text {th }}$ day return.

\section{Discussion}

Endonasal Endoscopic orbital surgery, however, is in its infancy and is performed primarily via sinonasal approaches by ENT surgeons. Transnasal endoscopic approaches are well established for treatment of orbital complications of rhinosinusitis (Strek et al., 2008).

The discussion concerns the role and decision for surgery using the endonasal endoscopic sinus approach versus conservative therapy in management of orbital complications of rhinosinusitis. Another question is the definitive outcome of ophthalmic symptoms such as ophthalmoplegia with diplopia, reduced visual acuity and proptosis after endoscpic sinus surgery.

\subsection{Prevalence}

In our study, male patients were significantly more often affected than females $(1.5 / 1)$, a ratio that was higher than in other studies like Mortimore\&Wormald, 1997, Ogunleye et al., 2001, Eufinger\&Machten, 2001 and Sultz et al., 2009.

The question of why this happens has been repeatedly asked through the years, but there is still no definite explanation for this observation. It is believed that the female immune system is more proficient than that of males.

In contrast to most reported series, Mortimore\&Wormald, 1997 Moloney et al., 1987, , Spires\&Smith, 1986, Fearon et al., 1979 , we had more adults $(\mathrm{n}=19 / \%)$ than children $(\mathrm{n}=11 / \%)$.

\subsection{Diagnosis}

In our study, all of our patients had a CT or MRI scan, CT results correlated in all 20 cases with intraoperative findings.

In a study of Younis et al., 2002 concerning orbital complications, the predictive accuracy of a clinical diagnosis was $82 \%$ and the accuracy of CT was $91 \%$. In another study of Miaskiewicz et al., 2005, accuracy of a CT and MRI examination in correlation with an intraoperative view was only $86.7 \%$. Patt and Manning, 1991 reported four cases (of 159 patients with orbital complications in sinusitis) who developed permanent blindness following a false-negative CT result and a delay of surgery.

In our study, two patients with orbital cellulitis developed subperiosteal abscess under conservative therapy and they were surgically managed, this supports the opinion that
Orbital complications can develop even under antibiotic treatment stated by Sinclair and Berkowitz, 2007 who reported development of SPA after a median of 2.5 days of fever and 1.6 days of therapy.

\subsection{Stages of Orbital Complications}

In our study, which did not include outpatients, we observed14 (46.7\%) patients in stage I (orbital cellulitis) and $10(33.3 \%)$ in stage II (subperiosteal abscess) and stage III (orbital abscess) was observed in $6(20 \%)$ of patients.

The frequencies of SPA vary in literature from $8 \%$ reported in study done by Soliere et al., 1990 to $15 \%$ reported by Davis and Stearns, 1994. And of orbital abscess (stage III) from 0 to $6.2 \%$ reported in study done by Sobol et al., 2002 and study done by Oxford and McClay, 2005.

\subsection{Therapy}

Medical treatment in all patients consisted of intravenous broad spectrum antibiotics; this was also combined with intranasal decongestants and analgesics.

In our study the medical treatment consisted of IV ceftriaxone $(100 \mathrm{mg} / \mathrm{kg} / \mathrm{d}$ in 2 divided doses $)$, IV metronidazole $(7.5 \mathrm{mg} / \mathrm{kg} /$ dose twice daily) was added for anaerobes covering.

In a study done by Pjerin et al., 2013 medical treatment was initiated with a combination of cefalosporines, aminoglycosides.

In another study done by Nicholas et al., 2011 different antibiotic regimens were used as follow, three patients were treated with antibiotic monotherapy (ceftriaxone), but all others were treated with multiple antiobiotics, most commonly with the combination of a third generation cephalosporin and flucloxacillin. A smaller proportion 13 patients $(17 \%)$ were also treated with metronidazole. Other antiobiotic agents, including gentamicin, clindamycin or ticarcillin-clavulanic acid were used less frequently.

From the above, it is concluded that the initial antibiotic regimen can be modified if the response is inadequate or if the cultures dictate otherwise (Hollsten et al, 2008).

Miaskiewicz et al., 2005 stated that early start of effective therapy is decisive to avoid residual ophthalmic symptoms that can remain for a lifetime. There is consensus on primarily (initially) treating stage I (orbital cellulitis) conservatively with broad-spectrum antibiotics, but should be operated on if no improvement is observed after $24-48 \mathrm{~h}$ as reported by Stammberger,1993 and Grevers, 1998. Jackson and baker, 1986 observed in their study of 137 patients with stage I, a progression in $49 \%$ of the cases despite antibiotic therapy and development of an abscess in a few.

In our study, two patients with orbital cellulitis developed subperiosteal abscess under clinical conservative therapy and they were surgically managed and another two cases of orbital cellulitis showed progression under antibiotic therapy who were olso surgically managed.

Up to recently the majority of surgeons were convinced that stage II (subperiosteal abscess) is as well a primary indication 
for operation as stage III (orbital abscess) as was stated by Kastenbauer, 1992, Stammberger, 1993 and Mortimore\&Wormald, 1997. Yet Souliere et al., 1990 reported successful conservative treatment of SPA in $50 \%$ of children by conservative therapy and Caversaccio et al., 2005 in $67 \%$.

A meta-analysis by Coenraad\&Buwalda, 2009 of five authors showed a cure rate of SPA in children with conservative treatment alone ranging from 26 to $93 \%$ and with combined treatment of $95-100 \%$ (Souliere et al., 1990, Oxford \&McClay, 2006, Greenberg\&Pollard, 1998, Rahbar et al., 2001, Garcia \&Harris, 2000). These success rates, however, may have been skewed by the mean age of children in these studies, which was very low (2.9-6.4 or $<9$ years).

However, in our opinion, priority for conservative treatment of SPA in young children ( $<6$ years) needs to be further demonstrated and confirmed in more studies, regarding the actual age group, anatomical location of abscess, its size, and effect on ophthalmological manifestation at time of presentation, and these studies must include long-term outcome.

Underestimation of the situation in these cases will only delay operative therapy. Additionally, one must keep in mind that $\mathrm{CT}$ and even MRI may have a false-negative diagnostic rate for SPA of $10-15 \%$ of cases as was stated by Younis et al., 2002 and Miaskiewicz et al., 2005. As well as what was stated by Coenraad that combined treatment achieved the best results in her analysis.

\subsection{Type of Surgery}

All surgically indicated patients in our study were managed by Endonasal endoscopic sinus surgery and there was no need for extranasal operations.

Some studies such as the study done by Siedek et al., 2010 had 50 of $62(81 \%)$ endonasal endoscopic sinus surgery , 11 $(8 \%)$ combined (extra/endonasal) and $1(3 \%)$ extranasal operation; indication for extranasal access was palpebral abscess and an extended SPA.

\subsection{Outcome}

The overall hospital stay (adults and children) after endoscopic sinus surgery (4-6 days) was much shorter than hospital stay reported by other studies such as the study done by Pejerin Radovani et al., 2013 using external approaches eiher alone or in combination with endoscopic sinus surgery.

Regarding the objective assessment and evaluation of ophthalmological manifestations after endoscpic sinus surgery done in 20 patients.

\subsection{Proptosis}

Using plastic ruler method 8 of 14 patients complaining of proptosis preoperatively, proved marked improvement (proptosis declined 3-4 mm), 5 patients proved moderate improvement (proptosis declined 2-3 $\mathrm{mm}$ ), and 1 patient had no improvement. The overall mean recession in proptosis of the 14 patients was $3 \mathrm{~mm}$.

\subsection{Visual Acuity}

Ten of eleven patients complaining of diminution of vision preoperatively, showed marked improvement of vision while one patient showed no improvement.

\subsection{Test for Ocular Motility}

All of the nine patients suffering ophthalmoplegia preoperatively, showed marked improvement of Ocular motility postoperatively.

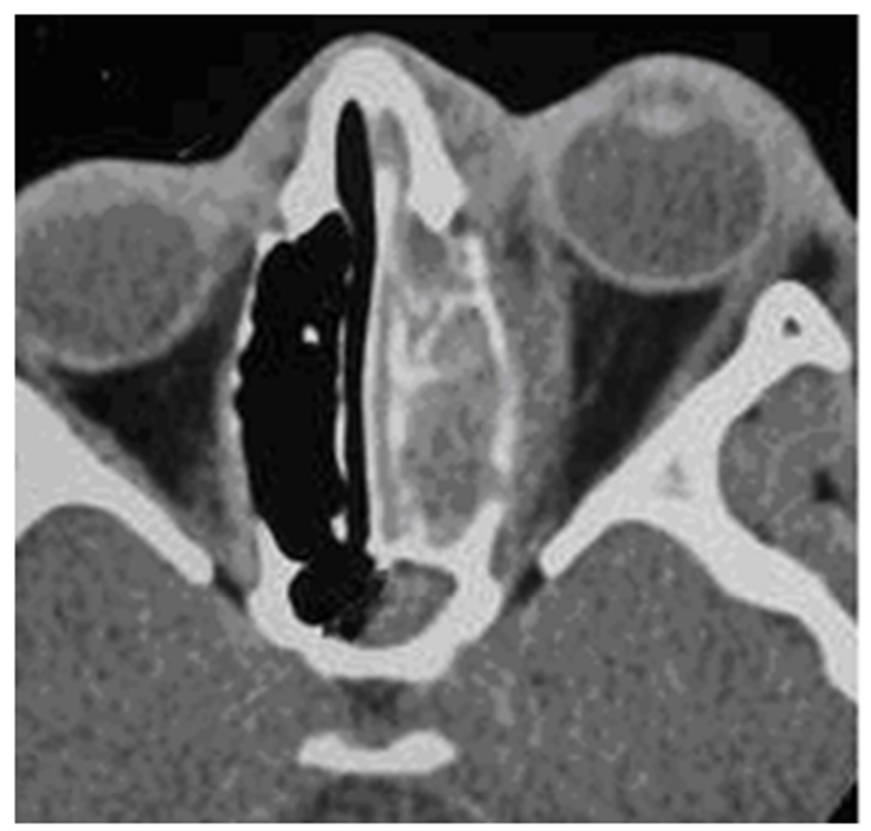

(A)

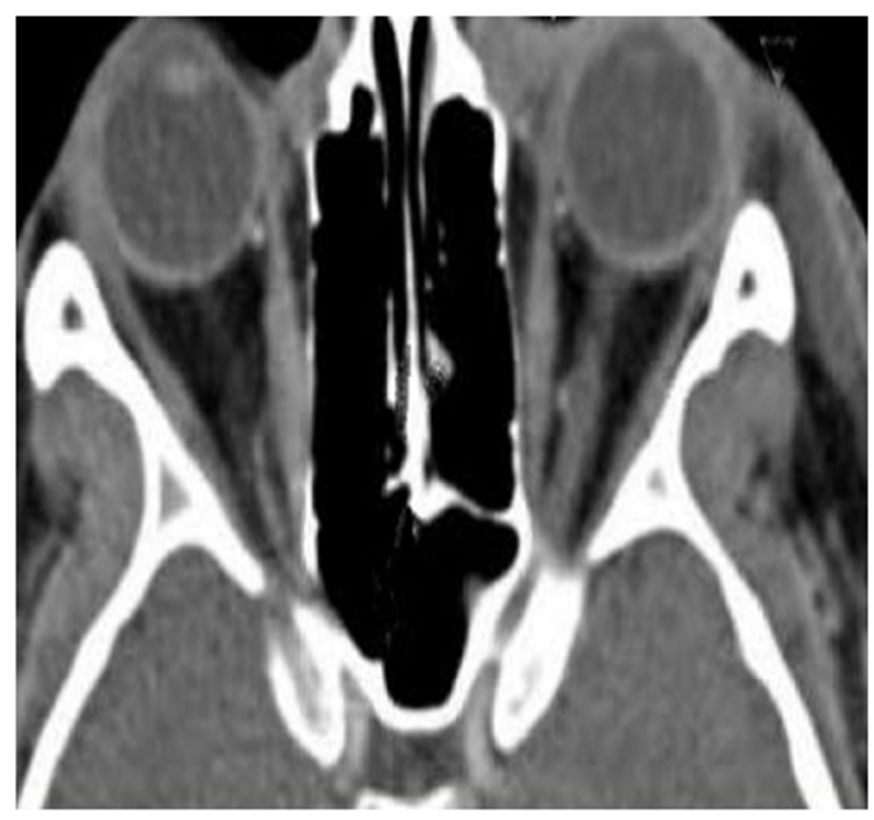

(B)

Figure 1. (A) Preoperative axial noncontrast CT domonstrating $L t$ ethmoiditis with Lt medial subperiosteal Abscess with proptosis. (B) Postoperative axial noncontrast CT scan of the sama patient after surgical drainage of abscess showing reduction of proptosis. 


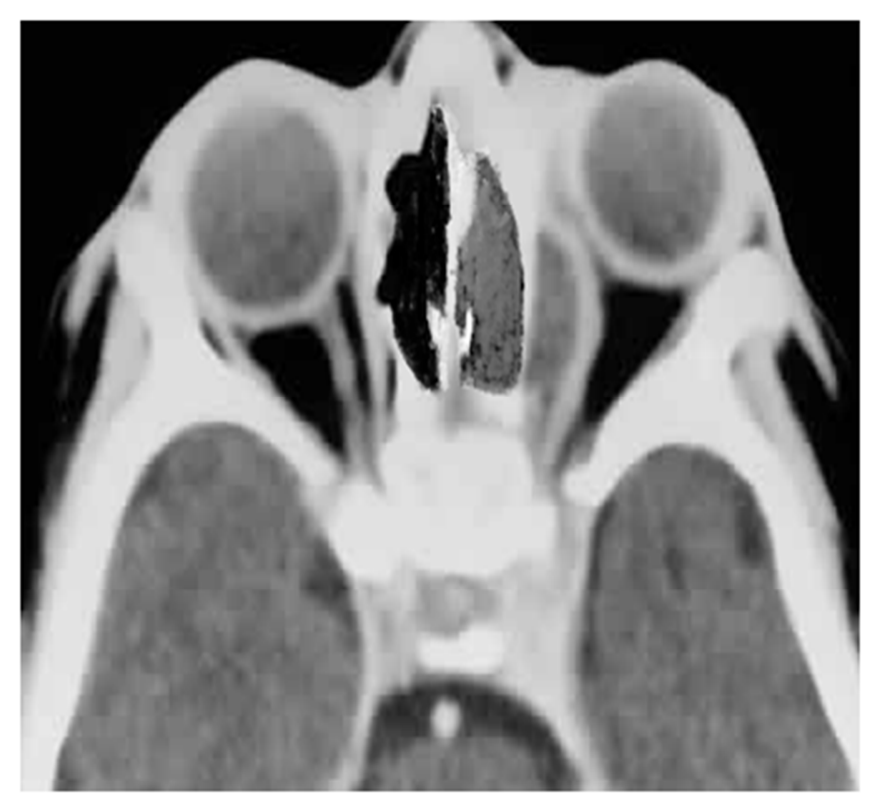

(A)

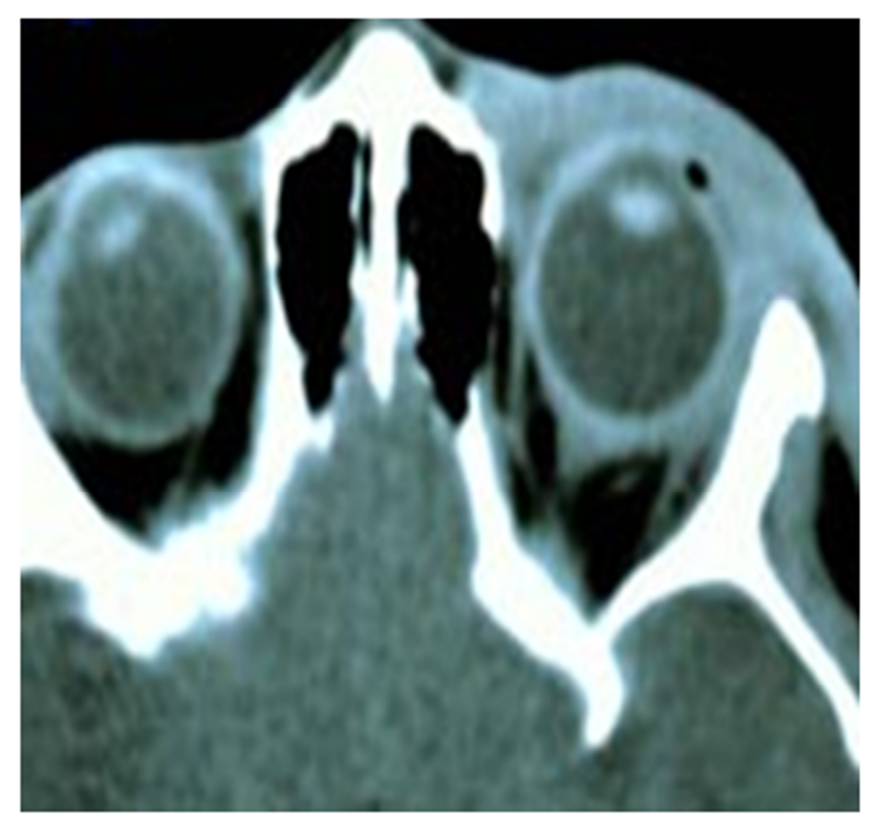

(B)

Figure 2. (A) Preoperative axial noncontrast CT demonstrating Lt ethmoiditis with Lt medial subperiosteal Abscess with proptosis. (B) Postoperative axial noncontrast CT scan of the same patient after ethmoidectomy and surgical drainage of abscess showing reduction of proptosis.

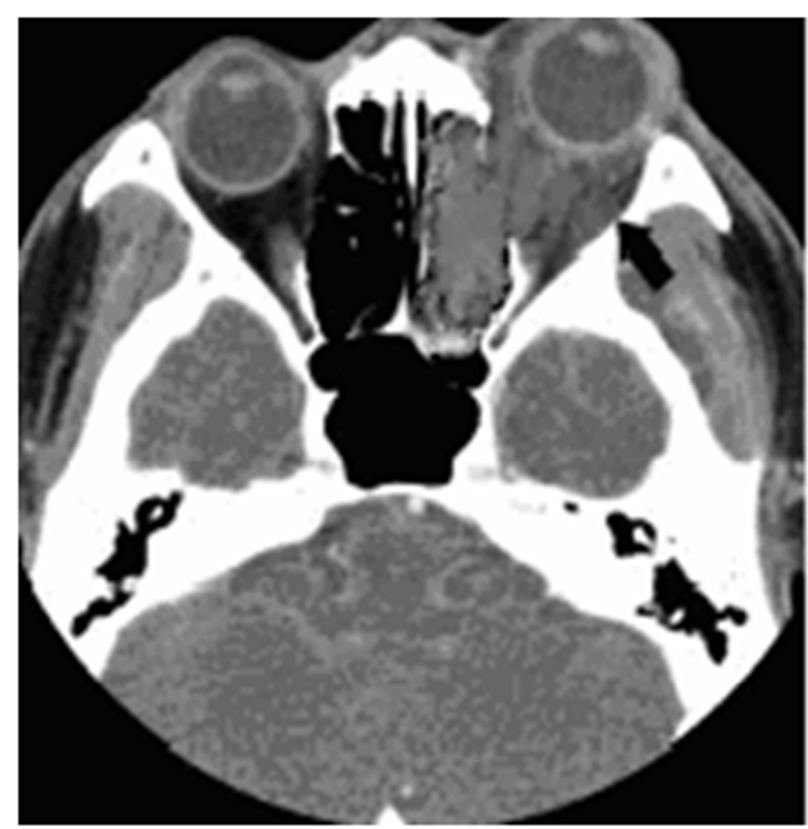

(A)

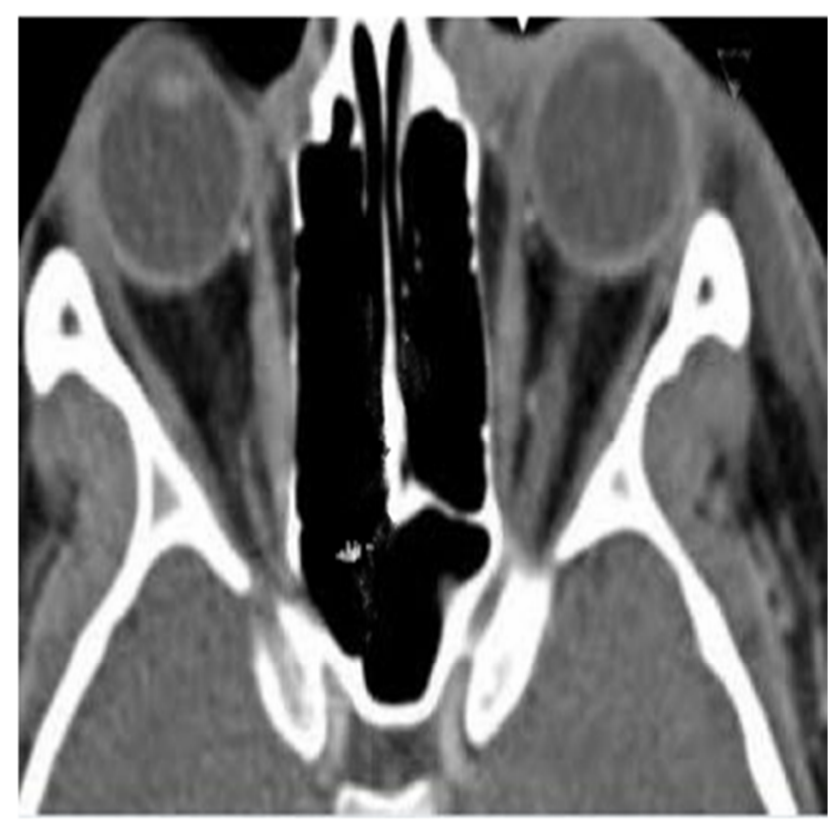

(B)

Figure 3. (A) Preoperative axial noncontrast CT demonstrates RT ethmoiditis with Rt intraorbital Abscess with proptosis. (B) Postoperative axial noncontrast CT scan of the same patient after ethmoidectomy and surgical drainage of abscess showing reduction of proptosis.

Table (1). Patient groups and treatment modalities.

\begin{tabular}{lllll}
\hline Stage and group & Diagnosis & N.of patients & Treatment \\
\hline I (group 1) & Orbital cellulites & 14 & 10 & Medical ttt \\
II (group2) & Subperiosteal abscess & 10 & 4 & EES \\
III (group 3) & Orbital abscess & 6 & EES & \\
\hline
\end{tabular}

EES: Endoscopic Endonasal Surgery

Medical ttt: Medical treatment. 
Table (2). Number of patients based on their indication(s) for surgical treatment in stages I-III of orbital complications due to rhinosinusitis.

\begin{tabular}{llll}
\hline & Stages & \\
\cline { 2 - 3 } & I & II \\
\hline CT proved abscess & $2(50 \%)($ passed from I to II) & $10(100 \%)$ & III \\
diminution of visual acuity & $2(50 \%)$ & $4(40 \%)$ & $5(83.3 \%)$ \\
Lac of response or clinical deterioration after 24hrs & $2(50 \%)$ & --- & 10 \\
Total & $4(100)$ & -- & 6 \\
\hline
\end{tabular}

Table (3). Summary of postoperative (endoscopic endonasal surgery) outcomes.

\begin{tabular}{lllll}
\hline Outcome & patients no=20 & Marked improvement & Improved & Unchanged or worsen \\
\hline Proptosis & 14 & $8(\%)$ & $5(\%)$ & $1(\%)$ \\
Visual acuity & 11 & $10(\%)$ & ------ & $1(\%)$ \\
Ocular Motility & 9 & $8(\%)$ & 1 & $-1 \%-$ \\
Diplopia & 10 & $5(\%)$ & 1 & 4 \\
\hline
\end{tabular}

Table (4). Statistical comparison adult and children in surgical groups as regards Hospital stay.

\begin{tabular}{|c|c|c|c|c|c|}
\hline & \multicolumn{3}{|c|}{ Surgical group } & \multirow[b]{2}{*}{ Mann Whitney U } & \multirow[b]{2}{*}{ P value } \\
\hline & $\begin{array}{l}\text { Adult } \\
N=15\end{array}$ & $\begin{array}{l}\text { Children } \\
\mathbf{N}=\mathbf{5}\end{array}$ & $\begin{array}{l}\text { Total } \\
\mathbf{N}=\mathbf{2 0}\end{array}$ & & \\
\hline $\begin{array}{l}\text { Hospital stay /days } \\
\mathrm{X} \pm \mathrm{SD} \\
\text { Range }\end{array}$ & $\begin{array}{l}5.27 \pm 0.59 \\
4-6\end{array}$ & $\begin{array}{l}4.60 \pm 0.55 \\
4-5\end{array}$ & $\begin{array}{l}4.98 \pm 0.57 \\
4-6\end{array}$ & 1.99 & $\begin{array}{l}0.046 \\
\mathrm{~S}\end{array}$ \\
\hline
\end{tabular}

\subsection{Diplopia}

Six of ten patients suffering diplopia preoperatively, showed resolution of diplopia, while four patients showed no change despite improvement of ocular motility.

These marked improvements in ophthalmological symptoms were evaluated 2 months postoperatively and they were comparable to outcome reported in many studies in which the surgical intervention was in the form of either external approach alone or combined external and endoscopic approaches such as study done by Siedek et al., 2010.

Our results confirm that endoscopic sinus surgery offers a convenient, safe, and effective alternative to open procedures, provide earlier return to normal life activity and work and can be successfully performed in well-selected cases of orbital complications of rhinosinusitis.

\section{Conclusion}

Endoscopic Sinus Surgery offers a convenient, safe, and effective alternative to open procedures and can be successfully performed in well-selected cases of orbital complications of rhinosinusitis with the following advantages

- Minimally invasive techniques in surgery.

- Reduced morbidity of extensive tissue dissection.

- Achieve a better cosmetic outcome.

- Shorter postoperative hospital stays with earlier return to both normal daily home activity and to work.

\section{References}

[1] Caversaccio M, Heimgartner S and Aebi C: Orbital complications of acute pediatric rhinosinusitis: medical treatment versus surgery and analysis of the computer tomogram Laryngorhinootologie. 2005; 84(11):817-21.
[2] Chandler JR, Langenbrunner DJ, Stevens ER: The pathogenesis of orbital complications in acute sinusitis. Laryngoscope. 1970; 80(9):1414-28.

[3] Coenraad S, Buwalda J: Surgical or medical management of subperiosteal orbital abscess in children: a critical appraisal of the literature. Rhinology.2009; 47:18-23.

[4] Davis JP, Stearns MP: Orbital complications of sinusitis: avoid delays in diagnosis. Postgrad Med J. 1994; 70:108-110.

[5] Eufinger H, Machtens E: Purulent pansinusitis, orbital cellulitis and rhinogenic intracranial complications. J Craniomaxillofac Surg. 2001 29(2):111-117.

[6] Fearon, B., Edmonds, B., Bird, R: Orbital-facial complications of sinusitis in children. Laryngoscope. 1979; 89: 947-953.

[7] Garcia GH, Harris GJ: Criteria for nonsurgical management of subperiosteal abscess of the orbit: analysis of outcomes 1988-1998. Ophthalmology.2000; 107:1454-1458.

[8] Greenberg MF, Pollard ZF: Medical treatment of pediatric subperiosteal orbital abscess secondary to sinusitis. J AAPOS.1998; 2:351-355.

[9] Grevers G: Rhino-sinugene Komplikationen In: Grevers G (Hrsg.) Praktische Rhinologie. Urban and Schwarzenberg, Mu "nchen, Wien, Baltimore. 1998;pp 153-164.

[10] Hollsten J, Hollsten D, Green, MK: Orbital community-acquired methicillin-resistant Staphylococcus aureus infections: the range of presentation, increasing prevalence and efficacy of treatment. Poster at Fall Scientific Symposium, American Society of Ophthalmic Plastic and Reconstructive Surgery. 2008.

[11] Jackson K, Baker SR: Clinical implications of orbital cellulitis. Laryngoscope. 1986; 96:568-574.

[12] Kastenbauer E: Komplikationen der Entzündungen der Nasennebenho"hlen und des Oberkiefers. (German) Naumann HH, Helms J, Herberhold C, Kastenbauer E (Hrsg.) Oto-Rino-Laryngologie in Klinik und Praxis. Bd 2 Thieme, Stuttgart, New York. 1992; pp 234-264. 
[13] Mias'kiewicz B, Lukomski M, Starska K, Jo'zefowicz-Korczyn'ska M: Orbital complications in acute and chronic sinusitis. H Pol Merkur Lekarski. 2005; 19(111):388-389.

[14] Moloney JR, Badham NJ, McRae A: The acute orbit. Preseptal (periorbital) cellulitis, subperiostal abscess and orbital cellulitis due to sinusitis. J Laryngol Otol Suppl. 1978; 12:1-18.

[15] Mortimore S, Wormald PJ: The Groote Schuur hospital classification of the orbital complications of sinusitis. J Laryngol Otol. 1997; 111:719-23.

[16] Nicholas J Potter NJ, Brown CL, McNab AA, Ting SY: Orbital Cellulitis: Medical and Surgical Management. J Clinic Experiment Ophthalmol. 2011; S2:001. doi:10.4172/2155-9570.S2-001.

[17] Ogunleye AO, Nwaorgu OG and Lasisi AO: Complications of sinusitis in Ibadan, Nigeria. West Afr J Med. Apr-Jun. 2001; 20(2):98-101.

[18] Oxford LE, McClay J: Complications of acute sinusitis in children, Otolaryngol. Head Neck Surg. 2005; 133 (1) 32-37.

[19] Oxford LE, McClay J: Medical and surgical management of subperiosteal orbital abscess secondary to acute sinusitis in children. Int J Pediatr Otorhinolaryngol. 2006; 70:1853-61.

[20] Patt BS, Manning SC: Blindness resulting from orbital complications of sinusitis. Otolaryngol Head Neck Surg. 1991; 104(6):789-795.

[21] Pjerin Radovani, Dritan Vasili, Mirela Xhelili, Julian Dervishi Balkan Med J: orbital complications of sinusitis. 2013 30:151-4.DOI:10.5152/balkanmedj.8005.

[22] Rahbar R, Robson CD, Petersen RA, DiCanzio J, Rosbe KW, McGill TJ et al: Management of orbital subperiosteal abscess in children. Arch Otolaryngol Head Neck Surg. 2001; 127:281286.

[23] Siedek V, Kremer A, Betz CS, Tschiesner U, Berghaus A, Leunig A : Management of orbital complications due to rhinosinusitis. Eur Arch Otorhinolaryngol. 2010; 267:1881-6.
[24] Sinclair CF, Berkowitz RG: Prior antibiotic therapy for acute sinusitis in children and the development of subperiosteal orbital abscess. Int $\mathrm{J}$ Pediatr Otorhinolaryngol. 2007; 71(7):1003-1006.

[25] Sobol SE, Marchand J, Tewfik TL, Manoukian JJ, Schloss MD: Orbital complications of sinusitis in children. J Otolaryngol. 2002; 31(3):131-136.

[26] Souliere CR Jr, Antoine GA, Martin MP, Blumberg AI, Isaacson G: Selective non-surgical management of subperiosteal abscess of the orbit: computerized tomography and clinicalcourse as indication for surgical drainage. Int $\mathrm{J}$ Pediatr Otorhinolaryngol. 1990; 19(2):109-119.

[27] Spires JR, Smith RJ: Bacterial infections of the orbital and periorbital soft-tissues in children. Laryngoscope. 1986; 96:763-8.

[28] Stammberger H: Complications of inflammatory paranasal sinus diseases including iatrogenic-induced complications. Eur Arch Otolaryngol Suppl. 1993; 1:61-102. Review, German.

[29] Strek P, Zagólski O, Składzień J, Kurzyński M, Oleś K, Muszyński P, Konior M, Hydzik-Sobocińska K: Orbital complications of sinusitis treated endoscopically. Przegl Lek. 2008; 65(5):221-4.

[30] Sultesz M, Csakanyi Z, Majoros T, Farkas Z, Katona G: Acute bacterial rhinosinusitis and its complications in our pediatric otolaryngological department between 1997 and 2006. Int J Pediatr Otorhinolaryngol. 2009; 73:1507-1512.

[31] Velasco e Cruz AA, Demarco RC, Pereira FC, Santos AC, Anselmo-Lima WT, Marquezini RM: Orbital complications of acute rhinosinusitis: a new classification Rev. Bras. Otorrinolaringol. 2007; vol.73 no.5 São Paulo Sept. /Oct.

[32] Younis RT, Lazar RH, Bustillo A, Anand VK: Orbital infection as a complication of sinusitis: are diagnostic and treatment trends changing? Ear Nose Throat J. 2002 Nov; 81(11):771. 